\title{
The CSR Evaluation System Research: Based on the Data of Chinese Listed Company 2014
}

\author{
Guo Xiangyu ${ }^{1}$, Xu Chenjie ${ }^{2}$ \\ ${ }^{1}$ School of Economics, Shanghai University, Shanghai, China \\ ${ }^{2}$ Bank of Communications Co., Ltd. Shanghai Branch, Shanghai, China
}

\section{Email address:}

gxiangy@hotmail.com (Guo Xiangyu),xcj910207@163.com (Xu Chenjie)

\section{To cite this article:}

Guo Xiangyu, Xu Chenjie. The CSR Evaluation System Research: Based on the Data of Chinese Listed Company 2014. Science Innovation. Vol. 5, No. 1, 2017, pp. 1-8. doi: 10.11648/j.si.20170501.11

Received: December 24, 2016; Accepted: January 20, 2017; Published: February 10, 2017

\begin{abstract}
Since the question of corporate social responsibility (CSR) was put forward, it has become one of the key point of academic research field. But Chinese corporations only pay attention to this problem in a relatively short time, and more focusing on the definition and theoretical analysis. This article chose all the eligible listed A-shares which was issued before the end of 2014 in Shanghai and Shenzhen stock market as samples, using the method by connecting corporate social responsibility indicator and financial indicators to establish a CSR evaluating system. In order to analysis the Chinese A-share listed companies' performance of corporate social responsibility.
\end{abstract}

Keywords: CSR, Evaluating System, Listed Company

\section{企业社会责任评估系统研究：以中国2014年上市公司数据为例}

\section{郭翔宇 ${ }^{1}$, 徐晨杰 ${ }^{2}$}

${ }^{1}$ 经济学院, 上海大学, 上海, 中国

2交通银行股份有限公司上海分行, 上海, 中国

邮箱

gxiangy@hotmai1.com（郭翔宇）, xcj910207@163.com（徐晨杰）

摘要: 自企业社会责任这一问题被提出至今, 已经成为了学界研究的重点, 但中国关注这一问题的时间相对较短, 更 多的是集中于概念界定与理论分析。本文选择了中国沪深两市所有符合条件的在 2014 年底前上市的A股为样本, 通过连 接企业的社会责任指标和财务指标来建立企业社会责任的评估系统, 以此对中国A股上市公司履行企业社会责任的情况 进行分析研究。

关键词：企业社会责任（CSR），评估系统，上市公司

\section{1. 引言}

随着全球经济的不断发展, 上市公司已成为世界经济 发展过程中不可或缺的一部分, 正扮演着越来越重要的作 用, 然而与上市公司大力拓展自身业务, 扩大经营范围相
对应的, 是其在企业社会责任上的问题也越来越受到来自 社会的关注，上市公司的劳工问题、环境污染问题、逃税 问题、贿赂问题近些年屡见不鲜，这一系列问题的爆发凸 显了对应企业的社会责任缺失。固然从追求利润最大化的 角度来看恪守企业社会责任会带来一定成本的增加, 但事 实上却不能简单的如此衡量, 积极履行他们相应承担的社 
会责任将帮助公司本身树立良好的社会形象, 从长久来看可 以更稳固的赢得消费者的信任, 更好的打开市场。在中国, 对企业社会责任的关注起步较晚, 相关的法律法规尚不健全, 因此上市公司的社会责任履行披露尚不规范。因此，建立一 个合理的上市公司企业社会责任评估系统十分必要。

\section{2. 文献综述}

\section{1. 企业社会责任概述}

最早提出社会责任这一思想的是Smith A.（1776）[1]， 他认为企业应尽可能的提高资源利用效率以提供社会需 求的产品和服务, 并以消费者认为的理想价格出售给他们, 这就是履行了企业所应承担的的社会责任。可以说, 这是 社会责任的一个维形, 但当时的社会经济结构并不复杂, 生产水平是极大制约企业发展的一道瓶颈，但随着经济的 发展, 一味追求利润最大化带来了生态环境恶化、资源分 配不合理等一系列问题, 反而不能为企业带来更高的利润, 此时学者们开始探索新的企业发展目标, 他们关注的目光 转向了商业伦理。

Carrol（1991）[2]应用金字塔理论对企业社会责任 做了进一步的界定，他将企业社会责任分为经济责任、法 律责任、伦理责任和慈善责任四方面, 并按金字塔形状从 低向高排列, 以示责任水平逐步递增。由于Carrol也认同 对于企业家来说获取经济利益是他们开展经济活动的根 本目的, 因而经济责任是企业最基本的责任, 以盈利为目 的, 他们几乎所有的活动均建立在这一目的上。在经济责 任之上, 企业还必须遵守国家或地区的相关法律法规, 这 又是企业在经营中需注意的基本规则, 这就是企业的法律 责任, 它建立在守法的基础上, 表现为企业遵守经济秩序 进行经营活动。企业的伦理责任简单的来说就是要求企业 行事合乎伦理, 避免损害包括消费者、员工在内的利益相 关者的利益, 虽然经济责任、法律责任中都包含了部分伦 理责任, 但伦理责任中更包括了在经营与法律条文中未被 纳入但大众所期待的部分, 因此其位于更上的地位。慈善 责任的本质是成为一个良好的企业公民，如对教育活动的 资助。Carro1的企业社会责任定义被众多学者所接纳, 且 时至今日仍然可被加以扩展应用 [3]。

自提出企业社会责任的概念后, 国内外学者不断进行 完善, 但是却尚不能达成一个统一的界定, 直到 2010 年 9 月12日国际标准化组织（IS026000）通过了社会责任的国 际标准草案, 对社会责任有了明确定义, 这一标准指出社 会责任的主体是组织, 组织在遵守适用法律并与国际行为 规范一致的前提下, 要充分考虑利益相关方的期望, 通过 将社会责任理念融入组织及组织各种活动涉及的各种关 系之中, 促进可持续发展和增进社会健康和福利 ${ }^{1}$ 。

\section{2. 企业社会责任实证研究综述}

Margolis、Walsh（2001）[4]对企业社会表现与财务 绩效进行了实证研究，发现50\%呈正向关系，剩下的25\%、

1 资 料 来 源 : ISO 26000-Social responsibility， http://www. iso. org/iso/social_responsibility
$20 \% 、 5 \%$ 分别为不相关、复杂与负向关系，虽然这一结论 并不能使我们显著构建企业社会表现与其财务绩效之间 关系，但 $50 \%$ 的正相关一定程度上还是显示了企业承担社 会责任有助于提升其财务绩效。Moskowitz（1972） [5] 通过对67家公司的研究发现, 承担较多社会责任的公司, 其平均股票回报也相对较高, 进一步得出了企业社会责任 与其股票价值呈正相关系的结论。与之相反的是, VanCe （1975）[6]以纽交所部分上市公司作为参照样本, 选取 Moskowitz（1972）研究样本中的一个子样本进行分析后 发现, 积极履行社会责任企业的股票市场表现却低于参照 样本, 由此他得出企业社会责任与其财务绩效负相关的结 论 [7]。从目前的实际情况来看, 我们不难得出, 跨国公 司企业社会责任水平与公司绩效应该呈正相关关系, 而 Moskowitz 与VanCe基本相同的样本却得出了不同的结论, 这或许与解释变量的选取, 误差项的剔除有关, 这一分歧 也从侧面说明了企业社会责任实证考察的复杂度, 这一结 论从后人的研究中亦可发现。

沈洪涛（2005）[8]以1997年至2003年沪深股市非金 融行业A股企业为研究样本, 在控制企业规模、行业、地 区和年份的基础上采用社会责任、市场业绩、会计业绩、 企业风险作为解释变量, 研究发现当期企业社会责任与财 务业绩显著正相关。同样相对的, 陈玉清、马丽丽 (2005)

[9]建立了社会责任贡献指标体系，从中国沪深股市上市 企业的社会责任与会计信息披露数据中抽取样本, 结果显 示企业社会责任贡献与公司价值并不相关，而且不同行业 之间的差异显著。从上世纪70年代到本世纪, 学者们的实 证研究尚不能达成一致, 尤其是研究样本趋同仍有此现象, 除计量方法上可能的偏差外, 可能与当时企业社会责任定 义尚不明确, 以致分析指标体系不够科学, 随着2010年 IS026000对企业社会责任的明晰, 此后对该问题的实证研 究结论应该会逐渐趋同。

从研究方法上来说, 李正 (2006) [10]采用的方法 是内容分析法中的指数法, 作者首先人为划分了企业社 会责任的多个表现类别, 如果企业在其年度报告中描述 了当年自身社会责任活动, 则赋分 1 , 若同时披露了对 应的金额则再加 1 分, 最后将各小类得分加总得到企业 的社会责任指数并进行比较。牛丽文等 (2008) [11]则 采用了模糊性的评价模型来衡量, 他们先是建立了一个 科学的因素集和评价集来描述企业履行社会责任活动, 接着进行权重的分配, 继而对这些因素分别评价, 从而 通过模糊矩阵对其进行综合评估, 得到最终的评价值, 而后又通过将此评价值与之前建立好的评价集进行对 比, 从而找到和此值相似的数值从而得到评价。由于“社 会责任” 这一尺标并不是那么具象, 这种赋分衡量的方 式有其可取之处, 但是显得不够严谨, 人为因素尚比较 浓重, 如今可以大量挖掘此前前人研究中被业界公认的 可用来衡量企业社会责任指标的论述, 仿照进行量化, 同时参考IS026000的定义指标, 以此更为科学的进行相 关性检验。此外, 对于其中可能存在的一些争议因素, 也可采取选用合适的工具变量、控制变量的方法进行弥 补检验, 增强文章的严谨性。 


\section{3. 上市公司企业社会责任评价指标构建}

上市公司企业社会责任标价体系中的指标应包括两 方面: 企业社会责任指标与上市公司财务指标。其中对企 业社会责任指标的选取主要依据IS026000的社会责任国 际标准量化, 其包含: 上市公司对员工的责任、对股东的 责任及对社会的责任。而上市公司的财务指标则广泛地选 取了尽可能多类别的反应公司经营业绩的财务指标，以期 能最大限度的挖掘能影响企业社会责任水平的指标集, 财 务指标的选取主要集中在六方面: 公司规模、盈利能力、 收益质量、偿债能力、营运能力与成长能力。

\section{1. 企业社会责任指标}

\subsection{1. 对员工的责任}

员工作为公司的直接利益相关者, 上市公司对其雇员 的发展也必然负有一定责任, 可以说公司对员工的基本经 济责任与法律责任共同组成了自身社会责任的底线。在本 文中, 使用薪酬相关的指标来衡量上市公司对员工的责任, 具体表现为考察其就业贡献率，计算公式为:

就业贡献率=支付给职工以及为职工支付的现金/平均净资产

在对企业财务指标的考察中可以发现，上市公司职工 薪酬可以分为实际支付与应付两部分, 其中应付职工薪酬 仅表明公司理应支付的部分，但由于种种原因尚未支付。 本文的考察重点是上市公司对员工的责任实现程度, 因此 对尚记为负债的 “应付职工薪酬” 部分不予考虑, 仅纳入 现金流量表中已发生的 “支付给职工以及为职工支付的现 金”部分作为指标考察。

\subsection{2. 对股东的责任}

上市公司的另一个直接利益相关方就是股东, 同时由 于它所具备的高度社会属性, 对于管理者来说, 他们不仅 需要保证公司的正常运转经营, 同时也必须兼顾股东对盈 余的要求权, 尤其是中小股东的权利要得到保证。在本文 中, 为了衡量企业对其股东的责任履行情况, 将其作为评 估系统的一部分, 所选用的指标为每股收益, 其计算公式 为:

$$
\text { 每股收益=净利润/总股本 }
$$

其中为了保证充分考虑到公司对所有股东的责任, 这 里的总股本包括了优先股、存量股等所有股种。

\subsection{3. 对社会的责任}

作为社会的一部分, 上市公司的社会责任绝不仅仅局 限在满足自身利益相关方的需求上, 它理应亦满足社会整 体平衡的需求。衡量公司履行最基本社会责任的一个尺度 即为照章纳税, 一些上市公司为了降低运营成本会主动寻 找避税机会, 甚至逃税, 那这就会使不同的上市公司对社 会的贡献处于不同的等级。当然, 上市公司的社会责任承 担是由多因素组成, 绝不仅于此, 但纳税情况是最能保证 可信度的一个价值尺度, 因此本文用税收比率来衡量上市 公司对社会的责任, 计算公式为:
税收比率=支付的各项税费/营业总收入

同衡量就业贡献率一样, 考察上市公司的税费也可分 为已支付的和应支付的两部分, 从衡量责任实现角度考虑, 这里将仅使用现金流量表中 “支付的各项税费” 部分纳入, 而舍弃资产负债表中的 “应缴纳税费” 部分。

\section{2. 上市公司财务指标}

上市公司之所以要承担社会责任其中的一个原因就 是因为它们需要对自身在经营活动中所耗用的社会资源 进行补偿, 而对社会资源的耗用程度就可以被其各种财务 指标所衡量。本文选取了六大类财务指标: 公司规模、盈 利能力、收益质量、偿债能力、营运能力与成长能力, 共 计 16 个具体指标, 以期尽可能多的发现影响企业社会责任 的指标集。上市公司具体财务指标如下:

表1 上市公司财务指标体系。

\begin{tabular}{llll}
\hline 财务分析类别 & 衡量指标 & 财务分析类别 & 衡量指标 \\
\hline \multirow{4}{*}{ 公司规模 } & 总资产对数 & & 资产负债率 \\
& $\begin{array}{l}\text { 净资产对数 } \\
\text { 总股本对数 }\end{array}$ & 偿债能力 & 流动比率 \\
& 净资产收益率 & & 现金比率 \\
\hline & 总资产报酬率 & 营运能力 & 存货周转率 \\
盈利能力 & 净利润/营业总 & & 收账款周转率 \\
& 收入 & & 总资产周转率 \\
\hline \multirow{3}{*}{ 收益质量 } & 经营活动净收益 & & 成长能力 \\
& $/$ 利润总额 & & 营业收入增长率 \\
& & & 总资产增长率 \\
\hline
\end{tabular}

\section{4. 上市公司企业社会责任评估系统实证分析}

\section{1. 样本选择}

本文选取2014年沪深两市A股上市公司财务数据为基 本样本统计指标, 因此需排除2015年1月1日及以后上市的 公司不计入本次样本。在此基础上, 考虑到上市公司本身 业绩较差的情况下一定会对其企业社会责任的履行产生 冲击, 这不在本文的考虑范畴中, 所以再剔除目前业绩不 好的样本 (即带有ST字样的公司), 最后排除数据不全的 公司, 得到本次计量分析的全部样本公司2255家。

\section{2. 分析方法与模型设计}

本文运用SPSS软件对沪深两市的符合条件的上市公 司的企业社会责任指标与财务指标进行相关与回归分析, 并以此建立一般评价模型加以评价。

本文构建的分析模型如下:

$Y_{n i}=A_{n 0}+A_{n 1} S_{n i}+A_{n 2} P_{n i}+A_{n 3} Q_{n i}+A_{n 4} D_{n i}+A_{n 5} O_{n i}+A_{n 6} G_{n i}$

其中: Y: 上市公司企业社会责任;

$S 、 P 、 Q 、 D 、 O 、 G:$ 公司规模、盈利能力、收益质量、 偿债能力、营运能力、成长能力;

$\mathrm{n}: 1,2,3$ (就业贡献率、每股收益、税收比率) ;

$\mathrm{i}: 1,2,3, \cdots \cdots, \mathrm{n}(\mathrm{n}=$ 样本数量 $)$ 


\section{3. 实证分析与结果}

\subsection{1. 上市公司对员工的责任}

经SPSS处理样本数据, 结果如下所示:

表2 就业贡献率相关分析。

\begin{tabular}{|c|c|c|c|c|c|}
\hline 指标 & & 就业贡献率 & 指标 & & 就业贡献率 \\
\hline 就业贡献率 & $\begin{array}{l}\text { Pearson相关性 } \\
\text { 显著性（双侧） } \\
N\end{array}$ & $\begin{array}{l}1 \\
2255\end{array}$ & 流动比率 & $\begin{array}{l}\text { Pearson相关性 } \\
\text { 显著性（双侧） } \\
\mathrm{N}\end{array}$ & $\begin{array}{l}-.069 * * \\
.001 \\
2255\end{array}$ \\
\hline 总资产对数 & $\begin{array}{l}\text { Pearson相关性 } \\
\text { 显著性（双侧） } \\
\mathrm{N}\end{array}$ & $\begin{array}{l}-.050 * \\
.017 \\
2255 \\
\end{array}$ & 现金比率 & $\begin{array}{l}\text { Pearson相关性 } \\
\text { 显著性（双侧） } \\
\mathrm{N}\end{array}$ & $\begin{array}{l}-.050 * \\
.017 \\
2255 \\
\end{array}$ \\
\hline 净资产对数 & $\begin{array}{l}\text { Pearson相关性 } \\
\text { 显著性（双侧） } \\
\mathrm{N}\end{array}$ & $\begin{array}{l}-.128 * * \\
.000 \\
2255\end{array}$ & 存货周转率 & $\begin{array}{l}\text { Pearson相关性 } \\
\text { 显著性（双侧） } \\
\mathrm{N}\end{array}$ & $\begin{array}{r}.005 \\
.822 \\
2255 \\
\end{array}$ \\
\hline 总股本对数 & $\begin{array}{l}\text { Pearson相关性 } \\
\text { 显著性（双侧） } \\
\mathrm{N}\end{array}$ & $\begin{array}{l}-.015 \\
.473 \\
2255\end{array}$ & 应收账款周转率 & $\begin{array}{l}\text { Pearson相关性 } \\
\text { 显著性（双侧） } \\
\mathrm{N}\end{array}$ & $\begin{array}{l}.009 \\
.653 \\
2255 \\
\end{array}$ \\
\hline 净资产收益率 & $\begin{array}{l}\text { Pearson相关性 } \\
\text { 显著性（双侧） } \\
\mathrm{N}\end{array}$ & $\begin{array}{l}.095 * * \\
.000 \\
2255\end{array}$ & 总资产周转率 & $\begin{array}{l}\text { Pearson相关性 } \\
\text { 显著性（双侧） } \\
\mathrm{N}\end{array}$ & $\begin{array}{l}.103 * * \\
.000 \\
2255\end{array}$ \\
\hline 总资产报酬率 & $\begin{array}{l}\text { Pearson相关性 } \\
\text { 显著性（双侧） } \\
\mathrm{N}\end{array}$ & $\begin{array}{l}-.011 \\
.600 \\
2255\end{array}$ & 营业收入同比增长率 & $\begin{array}{l}\text { Pearson相关性 } \\
\text { 显著性（双侧） } \\
\mathrm{N}\end{array}$ & $\begin{array}{l}-.023 \\
.274 \\
2255 \\
\end{array}$ \\
\hline 净利润/营业总收入 & $\begin{array}{l}\text { Pearson相关性 } \\
\text { 显著性（双侧） } \\
\mathrm{N}\end{array}$ & $\begin{array}{l}-.058 * * \\
.006 \\
2255\end{array}$ & 每股净资产增长率 & $\begin{array}{l}\text { Pearson相关性 } \\
\text { 显著性（双侧） } \\
\mathrm{N}\end{array}$ & $\begin{array}{l}-.007 \\
.726 \\
2255 \\
\end{array}$ \\
\hline $\begin{array}{l}\text { 经营活动净收益/利 } \\
\text { 润总额 }\end{array}$ & $\begin{array}{l}\text { Pearson相关性 } \\
\text { 显著性（双侧） } \\
\mathrm{N}\end{array}$ & $\begin{array}{l}.008 \\
.714 \\
2255\end{array}$ & 总资产增长率 & $\begin{array}{l}\text { Pearson相关性 } \\
\text { 显著性（双侧） } \\
\mathrm{N}\end{array}$ & $\begin{array}{l}-.014 \\
.509 \\
2255\end{array}$ \\
\hline 资产负债率 & $\begin{array}{l}\text { Pearson相关性 } \\
\text { 显著性（双侧） } \\
\mathrm{N}\end{array}$ & $\begin{array}{l}.149 * * \\
.000 \\
2255 \\
\end{array}$ & & & \\
\hline
\end{tabular}

*. 在 0.05 水平 (双侧) 上显著相关

**. 在0.01水平 (双侧) 上显著相关

表3 就业贡献率模型检验。

\begin{tabular}{lllll}
\hline 模型 & $\mathrm{R}$ & $\mathrm{R}$ 方 & 调整R方 & 标准估计的误差 \\
\hline 1 & $.241^{\mathrm{a}}$ & .058 & .057 & .32332 \\
\hline
\end{tabular}

a. 预测变量: (常量), 资产负债率, 净资产收益率, 净资产对数

表4 就业贡献率差异分析。

\begin{tabular}{lllllll}
\hline 模型 & & 平方和 & Df & 均方 & F & Sig. \\
\hline \multirow{3}{*}{1} & 回归 & 14.559 & 3 & 4.853 & 46.426 & $.000^{\mathrm{a}}$ \\
& 残差 & 235.306 & 2251 & .105 & & \\
& 总计 & 249.865 & 2254 & & & \\
\hline
\end{tabular}

a. 预测变量: (常量), 资产负债率, 净资产收益率, 净资产对数

b. 因变量: 就业贡献率

表5 就业贡献率回归系数。

\begin{tabular}{|c|c|c|c|c|c|c|}
\hline \multirow{2}{*}{ 模型 } & & \multicolumn{2}{|c|}{ 非标准化系数 } & \multirow{2}{*}{$\frac{\text { 标准系数 }}{\text { Beta }}$} & \multirow[b]{2}{*}{$\mathrm{T}$} & \multirow{2}{*}{ Sig. } \\
\hline & & B & 标准误差 & & & \\
\hline \multirow{4}{*}{1} & （常量） & .360 & .046 & & 7.844 & .000 \\
\hline & 净资产对数 & -.050 & .006 & -.172 & -8.226 & .000 \\
\hline & 净资产收益率 & .004 & .001 & .097 & 4.714 & .000 \\
\hline & 资产负债率 & .003 & .000 & .182 & 8.677 & .000 \\
\hline
\end{tabular}

a. 因变量: 就业贡献率 
根据分析结果得出就业贡献率与净资产对数、净资产 收益率以及资产负债率在 0.01 水平上相关, 据此建立回归 方程, 显著性水平 $\mathrm{F}=46.426$, 且相伴概率 $\mathrm{P}<0.01$, 净资产 对数、净资产收益率和资产负债率的 $\mathrm{t}$ 值分别为 $-8.226,4.714$ 和 8.677 , 且相伴概率 $\mathrm{P}<0.01$, 结果均显著, 建立方程如下:

$$
Y_{1}=0.36-0.05 X_{1}+0.004 X_{2}+0.003 X_{3}
$$

其中， $\mathrm{Y}_{1}$ ：上市公司就业贡献率;
$\mathrm{X}_{1}, \mathrm{X}_{2}, \mathrm{X}_{3}$ ：净资产对数、净资产收益率，资产负债 率

利用回归方程对所选样本上市公司就业贡献率进行 评价, 其中表现较好的上市公司为 922 家, 占样本公司数 的 $40.89 \%$, 表现较差的上市公司 1333 家, 占样本公司数的 $59.11 \%$ 。

\subsection{2. 上市公司对股东的责任}

经SPSS处理样本数据, 结果如下所示:

表6 每股收益相关分析。

\begin{tabular}{|c|c|c|c|c|c|}
\hline 指标 & & 每股收益 & 指标 & & 每股收益 \\
\hline \multirow{3}{*}{ 每股收益 } & Pearson相关性 & 1 & \multirow{3}{*}{ 流动比率 } & Pearson相关性 & -.005 \\
\hline & 显著性（双侧） & & & 显著性（双侧） & .807 \\
\hline & $\mathrm{N}$ & 2255 & & $\mathrm{~N}$ & 2255 \\
\hline \multirow{3}{*}{ 总资产对数 } & Pearson相关性 & $.295 * *$ & \multirow{3}{*}{ 现金比率 } & Pearson相关性 & .012 \\
\hline & 显著性（双侧） & .000 & & 显著性（双侧） & .577 \\
\hline & $\mathrm{N}$ & 2255 & & $\mathrm{~N}$ & 2255 \\
\hline \multirow{3}{*}{ 净资产对数 } & Pearson相关性 & $.338 * *$ & \multirow{3}{*}{ 存货周转率 } & Pearson相关性 & -.003 \\
\hline & 显著性（双侧） & .000 & & 显著性（双侧） & .870 \\
\hline & $\mathrm{N}$ & 2255 & & $\mathrm{~N}$ & 2255 \\
\hline \multirow{3}{*}{ 总股本对数 } & Pearson相关性 & $.067 * *$ & \multirow{3}{*}{ 应收账款周转率 } & Pearson相关性 & $.083 * *$ \\
\hline & 显著性（双侧） & .002 & & 显著性（双侧） & .000 \\
\hline & $\mathrm{N}$ & 2255 & & $\mathrm{~N}$ & 2255 \\
\hline \multirow{3}{*}{ 净资产收益率 } & Pearson相关性 & $.505 * *$ & \multirow{3}{*}{ 总资产周转率 } & Pearson相关性 & $.134 * *$ \\
\hline & 显著性（双侧） & .000 & & 显著性（双侧） & .000 \\
\hline & $\mathrm{N}$ & 2255 & & $\mathrm{~N}$ & 2255 \\
\hline \multirow{3}{*}{ 总资产报酬率 } & Pearson相关性 & $.527 * *$ & \multirow{3}{*}{ 营业收入同比增长率 } & Pearson相关性 & .027 \\
\hline & 显著性（双侧） & .000 & & 显著性（双侧） & .194 \\
\hline & $\mathrm{N}$ & 2255 & & $\mathrm{~N}$ & 2255 \\
\hline \multirow{3}{*}{ 净利润/营业总收入 } & Pearson相关性 & $.179 * *$ & \multirow{3}{*}{ 每股净资产增长率 } & Pearson相关性 & -.010 \\
\hline & 显著性（双侧） & .000 & & 显著性（双侧） & .621 \\
\hline & $\mathrm{N}$ & 2255 & & $\mathrm{~N}$ & 2255 \\
\hline \multirow{3}{*}{$\begin{array}{l}\text { 经营活动净收益/利 } \\
\text { 润总额 }\end{array}$} & Pearson相关性 & .031 & \multirow{3}{*}{ 总资产增长率 } & Pearson相关性 & .003 \\
\hline & 显著性（双侧） & .144 & & 显著性（双侧） & .877 \\
\hline & $\mathrm{N}$ & 2255 & & $\mathrm{~N}$ & 2255 \\
\hline \multirow{3}{*}{ 资产负债率 } & Pearson相关性 & -.004 & & & \\
\hline & 显著性（双侧） & .832 & & & \\
\hline & $\mathrm{N}$ & 2255 & & & \\
\hline
\end{tabular}

*. 在 0.05 水平 (双侧) 上显著相关

**. 在 0.01 水平 (双侧) 上显著相关

表 7 每股收益模型检验。

\begin{tabular}{lllll}
\hline 模型 & $\mathrm{R}$ & $\mathrm{R}$ 方 & 调整R方 & 标准估计的误差 \\
\hline 2 & $.731^{\mathrm{a}}$ & .534 & .533 & .32157 \\
\hline
\end{tabular}

a. 预测变量: (常量), 应收账款周转率, 总资产报酬率, 总股本对数, 资产收益率, 净资产对数, 总资产对数

表8 每股收益差异分析。

\begin{tabular}{lllllll}
\hline 模型 & & 平方和 & Df & 均方 & F & Sig. \\
\hline \multirow{2}{*}{2} & 回归 & 266.714 & 6 & 44.452 & 429.881 & $.000 \mathrm{a}$ \\
& 残差 & 232.457 & 2248 & .103 & & \\
& 总计 & 499.172 & 2254 & & & \\
\hline
\end{tabular}

a. 预测变量: (常量), 应收账款周转率, 总资产报酬率, 总股本对数, 净资产收益率, 净资产对数, 总资产对数 b. 因变量:每股收益 
表9 每股收益回归系数。

\begin{tabular}{|c|c|c|c|c|c|c|}
\hline \multirow{2}{*}{ 模型 } & & \multicolumn{2}{|c|}{ 非标准化系数 } & \multirow{2}{*}{$\begin{array}{l}\text { 标准系数 } \\
\text { Beta }\end{array}$} & \multirow{2}{*}{$\mathrm{t}$} & \multirow{2}{*}{ Sig. } \\
\hline & & $\mathrm{B}$ & 标准误差 & & & \\
\hline \multirow{7}{*}{2} & (常量) & 3.901 & .193 & & 20.253 & .000 \\
\hline & 总资产对数 & .126 & .017 & .348 & 7.229 & .000 \\
\hline & 净资产对数 & .213 & .019 & .523 & 11. 093 & .000 \\
\hline & 总股本对数 & -.324 & .013 & -.671 & -25.853 & .000 \\
\hline & 净资产收益率 & .016 & .002 & .271 & 10.082 & .000 \\
\hline & 总资产报酬率 & .027 & .003 & .301 & 10.855 & .000 \\
\hline & 应收账款周转率 & 1. $130 \mathrm{E}-5$ & .000 & .053 & 3.683 & .000 \\
\hline
\end{tabular}

a. 因变量:每股收益

根据分析结果得出每股收益与总资产对数, 净资产对 数, 总股本对数, 净资产收益率, 总资产报酬率和应收账 款周转率在0.01水平上相关，据此建立回归方程显著性水 平 $\mathrm{F}=429.881$, 且相伴概率 $\mathrm{P}<0.01$, 总资产对数, 净资产
对数, 总股本对数, 净资产收益率, 总资产报酬率和应收 账款 周 转率的 $\mathrm{t}$ 值分别为 $7.229,11.093$, $-25.853,10.082,10.855$ 和 3.683 , 且相伴概率 $P<0.01$, 结 果均显著, 建立方程如下:

$$
Y_{2}=3.901+0.126 X_{1}+0.213 X_{2}-0.324 X_{3}+0.016 X_{4}+0.027 X_{5}+0.0000113 X_{6}
$$

其中, $\mathrm{Y}_{2}$ : 上市公司每股收益;

$X_{1}, X_{2}, X_{3}, X_{4}, X_{5}, X_{6}$ : 总资产对数, 净资产对数, 总股本对数, 净资产收益率, 总资产报酬率, 应收账款周 转率

\subsection{3. 上市公司对社会的责任}

经SPSS处理样本数据, 结果如下所示:
利用回归方程对所选样本上市公司就业贡献率进行 评价, 其中表现较好的上市公司855家, 占样本公司数的 $37.92 \%$, 表现较差的上市公司 1400 家, 占样本公司数的 $62.08 \%$ 。

表10 税收比率相关分析。

\begin{tabular}{|c|c|c|c|c|c|}
\hline 指标 & & 税收比率 & 指标 & & 税收比率 \\
\hline 税收比率 & $\begin{array}{l}\text { Pearson相关性 } \\
\text { 显著性（双侧） } \\
\mathrm{N}\end{array}$ & $\begin{array}{l}1 \\
2255\end{array}$ & 流动比率 & $\begin{array}{l}\text { Pearson相关性 } \\
\text { 显著性（双侧） } \\
\mathrm{N}\end{array}$ & $\begin{array}{l}.134 * * \\
.000 \\
2255\end{array}$ \\
\hline 总资产对数 & $\begin{array}{l}\text { Pearson相关性 } \\
\text { 显著性（双侧） } \\
\mathrm{N}\end{array}$ & $\begin{array}{r}.016 \\
.459 \\
2255 \\
\end{array}$ & 现金比率 & $\begin{array}{l}\text { Pearson相关性 } \\
\text { 显著性（双侧） } \\
\mathrm{N}\end{array}$ & $\begin{array}{l}.103 * * \\
.000 \\
2255 \\
\end{array}$ \\
\hline 净资产对数 & $\begin{array}{l}\text { Pearson相关性 } \\
\text { 显著性（双侧） } \\
\mathrm{N}\end{array}$ & $\begin{array}{l}.056 * * \\
.008 \\
2255\end{array}$ & 存货周转率 & $\begin{array}{l}\text { Pearson相关性 } \\
\text { 显著性（双侧） } \\
\mathrm{N}\end{array}$ & $\begin{array}{l}-.018 \\
.396 \\
2255\end{array}$ \\
\hline 总股本对数 & $\begin{array}{l}\text { Pearson相关性 } \\
\text { 显著性（双侧） } \\
\mathrm{N}\end{array}$ & $\begin{array}{l}.047 * \\
.027 \\
2255 \\
\end{array}$ & 应收账款周转率 & $\begin{array}{l}\text { Pearson相关性 } \\
\text { 显著性（双侧） } \\
\mathrm{N}\end{array}$ & $\begin{array}{l}.052 * \\
.013 \\
2255 \\
\end{array}$ \\
\hline 净资产收益率 & $\begin{array}{l}\text { Pearson相关性 } \\
\text { 显著性（双侧） } \\
\mathrm{N}\end{array}$ & $\begin{array}{l}.175 * * \\
.000 \\
2255\end{array}$ & 总资产周转率 & $\begin{array}{l}\text { Pearson相关性 } \\
\text { 显著性（双侧） } \\
\mathrm{N}\end{array}$ & $\begin{array}{l}-.267 * * \\
.000 \\
2255\end{array}$ \\
\hline 总资产报酬率 & $\begin{array}{l}\text { Pearson相关性 } \\
\text { 显著性（双侧） } \\
\mathrm{N}\end{array}$ & $\begin{array}{l}.244 * * \\
.000 \\
2255 \\
\end{array}$ & 营业收入同比增长率 & $\begin{array}{l}\text { Pearson相关性 } \\
\text { 显著性（双侧） } \\
\mathrm{N}\end{array}$ & $\begin{array}{l}-.065 * * \\
.002 \\
2255\end{array}$ \\
\hline 净利润/营业总收入 & $\begin{array}{l}\text { Pearson相关性 } \\
\text { 显著性（双侧） } \\
\mathrm{N}\end{array}$ & $\begin{array}{l}.595 * * \\
.000 \\
2255 \\
\end{array}$ & 每股净资产增长率 & $\begin{array}{l}\text { Pearson相关性 } \\
\text { 显著性（双侧） } \\
\mathrm{N}\end{array}$ & $\begin{array}{l}-.011 \\
.586 \\
2255 \\
\end{array}$ \\
\hline $\begin{array}{l}\text { 经营活动净收益/利 } \\
\text { 润总额 }\end{array}$ & $\begin{array}{l}\text { Pearson相关性 } \\
\text { 显著性（双侧） } \\
\mathrm{N}\end{array}$ & $\begin{array}{l}.022 \\
.288 \\
2255 \\
\end{array}$ & 总资产增长率 & $\begin{array}{l}\text { Pearson相关性 } \\
\text { 显著性（双侧） } \\
\mathrm{N}\end{array}$ & $\begin{array}{l}-.010 \\
.637 \\
2255 \\
\end{array}$ \\
\hline 资产负债率 & $\begin{array}{l}\text { Pearson相关性 } \\
\text { 显著性（双侧） } \\
\mathrm{N}\end{array}$ & $\begin{array}{l}-.123 * * \\
.000 \\
2255\end{array}$ & & & \\
\hline
\end{tabular}

*. 在 0.05 水平 (双侧) 上显著相关

**. 在. 01水平 (双侧) 上显著相关 
表11 税收比率模型检验。

\begin{tabular}{lllll}
\hline 模型 & $\mathrm{R}$ & $\mathrm{R}$ 方 & 调整R方 & 标准估计的误差 \\
\hline 3 & $.630^{\mathrm{a}}$ & .396 & .395 & .06321 \\
\hline
\end{tabular}

a. 预测变量: (常量), 营业收入同比增长率, 流动比率, 总资产周转率, 净利润/营业总收入, 现金比率

表12 税收比率差异分析。

\begin{tabular}{lllllll}
\hline 模型 & & 平方和 & $\mathrm{df}$ & 均方 & $\mathrm{F}$ & Sig. \\
\hline \multirow{3}{*}{3} & 回归 & 5.900 & 5 & 1.180 & 295.389 & $.000 \mathrm{a}$ \\
& 残差 & 8.985 & 2249 & .004 & & \\
& 总计 & 14.885 & 2254 & & & \\
\hline
\end{tabular}

a. 预测变量: (常量), 营业收入同比增长率, 流动比率, 总资产周转率, 净利润/营业总收入, 现金比率

b. 因变量:税收比率

表13 税收比率回归系数。

\begin{tabular}{|c|c|c|c|c|c|c|}
\hline \multirow{2}{*}{ 模型 } & & \multicolumn{2}{|c|}{ 非标准化系数 } & \multirow{2}{*}{$\frac{\text { 标准系数 }}{\text { Beta }}$} & \multirow{2}{*}{$\mathrm{t}$} & \multirow{2}{*}{ Sig. } \\
\hline & & $\mathrm{B}$ & 标准误差 & & & \\
\hline \multirow{6}{*}{3} & （常量） & .072 & .003 & & 28.294 & .000 \\
\hline & 净利润/营业总收入 & .002 & .000 & .573 & 34. 048 & .000 \\
\hline & 流动比率 & .003 & .001 & .136 & 3. 156 & .002 \\
\hline & 现金比率 & -.004 & .002 & -.119 & -2.774 & .006 \\
\hline & 总资产周转率 & -.022 & .002 & -.160 & -9.492 & .000 \\
\hline & 营业收入同比增长率 & $-2.135 \mathrm{E}-4$ & .000 & -.098 & -5.943 & .000 \\
\hline
\end{tabular}

a. 因变量:税收比率

根据分析结果得出税收比率与总资产周转率与净利 润/营业总收入, 流动比率, 现金比率, 总资产周转率, 营业 收入同比增长率在0.01水平上相关, 据此建立回归方程显 著性水平 $\mathrm{F}=295.389$, 且相伴概率 $\mathrm{P}<0.01$, 总资产周转率
与净利润/营业总收入, 流动比率, 现金比率, 总资产周转 率, 营业收入同比增长率的 $\mathrm{t}$ 值分别为 $34.294,3.156$, $-2.774,-9.492,-5.943$, 且相伴概率 $P<0.01$, 结果均显 著, 建立方程如下:

$$
Y_{3}=0.072+0.002 X_{1}+0.003 X_{2}-0.004 X_{3}-0.022 X_{4}-0.0002135 X_{5}
$$

其中, $\mathrm{Y}_{3}:$ 上市公司税收比率;

$\mathrm{X}_{1}, \mathrm{X}_{2}, \mathrm{X}_{3}, \mathrm{X}_{4}, \mathrm{X}_{5}$ : 净利润/营业总收入, 流动比率, 现金比率, 总资产周转率, 营业收入同比增长率

利用回归方程对所选样本上市公司就业贡献率进行 评价, 其中表现较好的上市公司仅 855 家, 占样本公司数 的 $37.92 \%$, 表现较差的上市公司 1400 家, 占样本公司数的 $62.08 \%$ 。

\section{5. 结论}

本文基于IS026000企业社会责任定义的基础上, 从上 市公司的财务数据入手, 选择财务指标采用数学方法分析 上市公司企业社会责任的决定因素, 并建立相关的数学模 型, 从而对中国目前上市公司的企业社会责任履行情况做 一个较为客观的评价与分析。

通过本文分析，提出上市公司对员工、股东及对社会 的责任是分析上市公司企业社会责任的主要因素, 上市公 司在切实履行其社会责任的承担时, 这三个方面的责任是 它们可以重点关注的方向。通过实证检验, 发现中国上市 公司在对员工、股东及社会的责任的履行上总体表现均不 乐观, 其中最好的对员工的责任履行表现较好公司占比也 才 $40.89 \%$, 而对股东和社会的责任履行表现较好公司占比 更低, 都均为 $37.92 \%$ 。中国上市公司在企业社会责任的履
行上还有很长的路要走, 这需要政府、社会、公司、消费 者等多方面共同努力。

完善对上市公司经营的监管, 督促其按时准确通过半 年报与年报披露相关经营数据, 进一步推广行业自律都能 使得公司的经营更为规范, 更有可能获取更高的收益, 从 而推动其对员工与股东的责任履行。与此同时, 加大对企 业纳税的执法力度也能在一定程度上使得其对社会的责 任履行得以改善。

对上市公司的企业社会责任考察是一个复杂的综合性 评价问题，本文的评估系统构建与实证检验还存在一定的 问题, 最核心的问题是对被解释变量的解释度并不高, 这 一问题随着对指标的进一步科学调整应该可以得到有效的 修正。此外, 企业社会责任的履行情况应该是一个不断随 时间变化而变化的过程, 不同时期同一家上市公司的履行 情况可能会不同, 如何合理地将这一变化纳入考察体系中 尚需考量。最后, 由于影响企业社会责任的因素众多, 本 文仅从三个角度进行了分析, 其他因素在其中所起到的作 用及这些因素是否也应被纳入考察体系也需要进一步探讨。 


\section{参考文献}

[1] Smith A. An inquiry into the nature and causes of the wealth of nations $[J]$. London: George Routledge and Sons, 1776.

[2] Archie B. Carrol, 1991, The Pyramid of Corporate Social Responsibility: Toward the Moral Management of Organizational Stakeholders [J], Business Horizons (7-8), 39-48.

［3］阿齐B - 卡罗尔等著, 黄煜平等译, 《企业与社会, 伦理与 利益相关者管理》，机械工业出版社，2004。

[4] Margolis, J. D., Walsh, J. P., 2001. People and Profits: The Search for a Link Between a Company's Social and Financial Performance [J], Mid-American Journal of Business, 18 (1), 83-84.

[5] Moskowitz, Milton, R. Choosing Socially Responsible Stocks [J]. Business and Society Review. 1972. 1: 71-75.

[6] Vance S C. Are socially responsible corporations good investment risks [J]. Management review, 1975, 64 (8) : $19-24$.

[7] 温永. 跨国公司企业社会责任的动因阐释 [D]. 浙江大 学, 2013。

[8］沈洪涛. 公司社会责任与公司财务业绩关系研究——基于 相关利益者理论的分析 [M]. 福建: 厦门大学企业管理专 业. 2005:21-35。

[9］陈玉清.马丽丽. 我国上市公司社会责任会计信息市场反应 实证分析 $[J]$. 会计研究. 2005, 11:152-153。

[10］李正. 企业社会责任与企业价值的相关性研究: 来自沪市上 市公司的经验证据 [J]. 中国工业经济，2006（2）。

[11] 牛丽文, 符丹, 郭红英. 企业履行社会责任的评价指标体系 研究 [J]. 河北工程大学学报: 社会科学版, 2008, 25 (3)。

[12] 曹波. 企业社会责任及评估系统 [D]. 对外经济贸易大 学, 2007 。

[13] 洪旭, 杨锡怀. 中国企业社会责任评估系统的构建一一以沪 深两市上市公司为例 $[\mathrm{J}]$. 东北大学学报: 自然科学 版, 2011, 32 (11) : 1668-1672。

[14] 黄亚平, 雷婷婷. 我国企业社会责任评价指标体系的建立 [J]. 中国统计, 2009, (6) :26-28。

[15] 黄知然. 企业社会责任评估系统及其实证研究-一以湖北 省民营企业为例 [D]. 广西师范大学, 2014。

[16] 靳晓娜. 企业社会责任与企业成长性关系的实证研究 [D]. 西南财经大学会计学院, 2009。

[17] 宋建波, 盛春艳. 基于利益相关者的企业社会责任评价研究 - - 以制造业上市公司为例 $[\mathrm{J}]$. 中国软科 学, 2009, (10): 153-163。

[18］严复海, 赵麟. 企业社会责任绩效评价指标体系的构建 $[\mathrm{J}]$. 生产力研究, 2009, (2) : 146-148。

[19] 颜剩勇. 上市公司社会责任的财务评估系统 [J]. 财经科 学, 2007, (4) :66-72。

[20］曾嘉, 陈丽荣. 上市公司财务绩效与社会责任相关性的实证 研究 $[J]$. 商业会计, 2015, (6)。 